\title{
Variables Affecting the Payment Mechanism for Strategic Purchasing in the Indirect Health Section of Iranian Social Security Organization
}

\author{
Amir Ashkan Nasiripour (Corresponding author) \\ Department of Health Services Management, Science and Research Branch \\ Islamic Azad University, Tehran, Iran, P.O. Box: 14515-775 \\ Tel: 98-21-4486-9701Ｅ-mail: nasiripour@srbiau.ac.ir \\ Pouran Raeissi \\ School of Management and Medical Information Services \\ Tehran University of Medical Sciences, Tehran, Iran \\ Seyed Jamaladin Tabibi \\ Department of Health Services Management, Science and Research Branch \\ Islamic Azad University, Tehran, Iran \\ Khalegh Karimi \\ Ph.D. Student in Health Services Management, Science and Research Branch \\ Islamic Azad University, Tehran, Iran
}

Received: February 4, 2011 Accepted: February 18, 2011 doi:10.5539/ibr.v4n2p103

\begin{abstract}
The present study was conducted to define the variables affecting payment mechanism for strategic purchasing in the indirect health section of Iranian Social Security Organization of Iran, by which the Organization can provide the insured with better services while controlling the cost. 13 variables affecting payment mechanism for strategic purchasing were determined. A questionnaire was prepared based on above variables and completed by experts. The data was analyzed by SPSS and LISREL through confirmatory and exploratory analysis factors. The results indicate that payments mechanism is important in the process of strategic purchasing and three partial dimensions including performance-based payment mechanism, time-based payment system and risk coverage should be considered: 1Performance-based payment system includes variables such as financial incentives for health service providers, prospective payment system and performance-based motives for health service employees. 2-Time-based payment system includes variables such as the time of receiving service. 3. Risk coverage includes variables such as justice and financial protection against disease risk.
\end{abstract}

Keywords: Strategic purchasing, Payment mechanism, Performance-based payment

\section{Introduction}

Studies in the health field show that almost half of the health resources are allotted to $4 \%$ of population who are hospitalized annually (Hasanzade \& Fakhimzade, 2007). Iranian Social Security Organization has allocated the significant portion of Iranian health market. It consider as the second main producer and the greatest purchaser of health services throughout the country. $45 \%$ of resources are consumed for delivering services in direct health section and the 55\% remainder is spent for indirect health section. $37 \%$ of total credit in indirect health section is spent for in-patient services and more that $70 \%$ of resources are allocated to these patients.

According to the above statistics, more that $55 \%$ of health costs of the Organization are spent for delivering services to the insured through purchasing health services in indirect health section, which in return necessitates the existence of consolidated management in purchasing services (Statistical Indicators of Health Department, 2008).

At present, purchasing services in the Social Security Organization is carried out with regard to the definite annual budget and medical bills, but the growing costs of health services and the necessity of delivering necessary and qualified health services manifest the role of strategic purchasing process more than ever.

The increase in the costs of health services in the Social Security Organization in recent years, following the increase of the number of insured and the transference of advanced technologies from other countries, have become a challenge for the Social Security Organization, while taking into account the Organization's responsibility in providing insured, retirees and pensioners with health services; as a result, the optimum usage and compiling a logical mechanism based on the scientific standards in purchasing health services seem undeniable. The 
management of scarce resources in an effective way is one of the most important interfering mechanisms in health section.

The experiences indicate that without adopting a strategic policy and with a focus on payment mechanisms, poor and common individuals are probably ignored. Strategic purchasing is used as a tool in promoting the performance of health section and other economic sections. The experiences arisen from utilizing this tool has become successfully operational in developed countries (Preker \& Harding, 2003).

\subsection{The significance of the Subject}

Based on the international experiences, the advancement of sciences and development of new methods in surgical sciences, inventing numerous medicines and implementing other related operations, even in low income countries have had favorable results, but most of the implemented programs within the health filed, before applying to the poor people, have failed (Preker et al., 2007).

The market of health services has always faced numerous problems arising from the inefficient allocation of resources. One of the most significant reasons of this inefficiency is the asymmetry of information between consumers and users of health services (including patients, etc.) and health service providers (clinical centers, hospitals, doctors, etc). The asymmetry of existing information implies the inability of the users in discerning what kind of health care they need and what kind of health service is suitable for them (O'Neil \& Largey, 1998). Patients in a perfect market express their requests in payment through response to the demand. Providers of the services and producers of these conditions compete with each other in a perfect market model based on the principles of marketing, in a way that the expenses of these delivered services is in proportion to the volume and the amount of supply and demand (Langenbrunner et al., 2005).

\subsection{Objectives}

With regard to the importance of the payment mechanism for strategic purchasing in the indirect health section of Social Security Organization, the present study aims at defining the variables affecting payment mechanism for strategic purchasing in order to promote the performance of insurance organizations in providing health services and just distribution of the services among insured, so the Organization becomes able in providing insured with more qualitative services while controlling the costs.

\subsection{Theoretical Principles}

In examining the health and treatment status and related costs in the United States, it is believed that in managed care, insurance purchasers and insurers do not just draw check; they become involved in what number, from what type, and by which providers they receive care (Aaron, 1991). Moreover, purchasers and insurers decide how much service providers receive and how it is paid. Four main methods of payment for health care are: out of pocket, individual private insurance, employment-based group private insurance, government financing. These four methods can be considered as a historical evolution as well as finance classification for the current status of health care. Health care financing in the United States, following a series of social interventions, became more perfect until it got the modern form. From the historical point of view, each of the four methods of financing health care was created in a response to compensate for the insufficiency of the previous method.

Countries, through studying and evaluating various methods of payment, achieved a high level of knowledge in methods and the time of payment to the health care providers. Designing, management and implementation, as well as related reforms, have been considered in the process of strategic purchasing for transition from the current state of health systems. Three efficient and effective methods have been implied in the payment system of health service providers; these methods are: capitation payment system for basic health care, per-case payment system for hospital services, and hospital global budget.

\subsection{Payment Method}

Appropriate contract components to purchase services are: spot market for unpredictable cases, contracts to provide semi-support services for predictable cases, franchise method (agency) to standardize the needs in different places, communication contracts for purchasing, which are difficult to monitor (Preker \& Harding, 2003).

From the above discussions it is perceived that most of the goods and services in a perfect market show a degree of reduction in competitiveness and measurement. Governments possess the tools that can help solve these problems. Some of these tools are: providing necessary information, enactment of laws and regulations, contract to receive services, creating subsidies or direct financial relationship and beginning the production of public sector.

The results of the studies definitely show that payment system of service providers is defined by affecting the characteristics of goods through three key factors of internal incentives in organizations providing health care 
including: 1) distribution of the right of decision making about the created profit 2) contact with the market 3) Readiness to solve social functions.

Services delivered by providers give different responses to the payment mechanisms and substitute financing. For instance, group buying by health social insurance investment in Germany offers various messages to the service providers which are more than regular and organized competition in the United States, guided demand of consumers through out-of-pocket system in India, stored bills for medical services in Singapore and exclusive purchasing in England.

Following cases should be observed in order to prevent financial risks in the payment systems of health care service providers: risk coverage approach must be changed; it means it should change from low range to high range of risk coverage, poor people be supported. So, strategic purchasing leads to the improvement of results and accountability in health system (WHO Report, 2000).

\subsection{Payment Methods and Payment Incentives}

There are three ways of payment to a service provider: 1- patient's direct payment to the service provider 2- patient's direct payment to the provider and then paying back the whole or a part of the cost 3-direct payment to the provider through "allocation of resources and purchasing services" mechanism along with a limited franchise or patient's informal cost (WHO Report, 2000).

\subsection{Appropriate Payment Method}

At first step, the buyer decides about the policy objectives such as: resources, efficiency, costs' reduction and access to quality and simplicity of implementation or a combination of these. The payment system should be in line with the achievement of one or several objectives mentioned above. The buyer considers the payment mechanism in two axes: payment unit and payment level.

Payment unit can be fully clear such as: number of visits or tests. Payment unit may be cumulative such as: a period of care or the needed services within a span of time like a year.

Payment level is based on standard and expected cost of services, number of providers, competition between providers, volume of health product, appropriate information at hand, and patient's ability to participate in costs. (Barnum et al., 1995) (Table1).

Table 2 shows the common payment mechanisms. Creating motives and incentives factors to achieve other objectives in payment system are necessary when line item budget method is effective in controlling the costs. The above objectives are: preventing the problems of health filed for members and beneficiary groups in this field, delivering services and solving the members' problems, responding to the patients' legal expectations and reducing costs.

Capitation payment is a kind of fixed payment system which defines the responsibility of health care providers within a vast range of delivered services. This method is an incentive factor to control costs and prevent unnecessary expenditures. Due to the advantages of capitation system in controlling costs, capitation method is used in some organizations purchasing services in the world. This method has become operational in England National Medicine (Robinson \& Grand, 1994), and the network of service providers in Social Security Organization of Argentina (World Bank Report, 1998), non-affiliated organizations in New Zealand (Wilton \& Smith, 1998) and the organizations of health care providers in the United States (Feachem, 2000).

\subsection{Purchasing and Methods of Payment to Health Care Providers}

Patients in a perfect market bring up their needs in payment through responding to demand. Providers of these services and producers of such conditions compete with each other based on marketing principles; in a way that the costs related to the delivered services is proportionate to the volume and the level of supply and demand. The advantage of patients' direct payment of health costs and services is that it conveys a clear message to the patients about the fee of the service. Therefore, the individual providing these services is fully aware of the existing requests. The major problem is the destitute patients or the high care costs in cases of special diseases; these costs are not finished all at once; they are spent in a definite time span in order to receive partial or full compensation during a treatment process and are received by the hospital (Langenbrunner et al., 2005).

According to the studies taken, buyers should shift their direction from fee-for-service payment mechanisms to those mechanisms covering risks. In order to create and establish mechanism payment systems, particularly in public sectors, special techniques, particular organizational capacities and accountability are needed (WHO Report, 2000).

A research was taken by Buss in 2004 which examined the strategic purchasing process about which services, how, how much and from whom are bought. Payment system issues, allocation of resources, contracts, and result-based 
and performance-based systems were taken into consideration in the survey. The question "who pays the cost for health system?" and selecting payment system for health care costs have been mentioned in the World Health Report 2000. The discussion has emphasized on subsidy payment to patients and poor individuals with low income. Moreover, it pays attention to strategic purchasing in health services to promote results, health system performance and accountability. In another section, different payment mechanisms including line item budget, global budget, capitation and fee-for-service have been taken into account (WHO Report, 2000).

Payment based on the efficiency of activities (result-based payment) instead of payment based on the costs is the result of a research carried out in 2008 in Portugal by Borges and Kondoso. New competition market is a kind of payment system of hospital services introduced in September 2004 by groups of health care producers in England (Boyle, 2007). About $10 \%$ of the population, due to out-of-pocket costs, has gone below the poverty line and more than $20 \%$ of the income of $7 \%$ of the population, particularly in countries with low per-capita income, is spent for medical expenditures. According to the above report, the impact of out-of-pocket payment system should be evaluated. A framework of contract and methods of payment have been introduced in Estonia in relation to various incentive factors compatible with kinds of health care providers (Habicht et al., 2005). Methods of payment for service providers are being developed increasingly in this country. These changes generally have legal origins and are coordinated. Similar to most developed countries, most efforts are done to find the best solution for paying more to best results. For example, the method of payment to general physicians including capitation method which is based on age right now and fee-for-service method as an incentive factor to perform extra care at the level of primary care are used.

Payment method in hospital care is defined by in-patient days in the hospital. At present, the system is based on diagnostic related groups which is a balancing and incentive factor (Grignon et al., 2004). The major problem of payment to health providers in Estonia is that the individuals are not satisfied. Justice in accessing services and resources of health section should be observed. Examining methods of payment in Australia shows that fee-for-service is a common method for paying general physicians and advanced private care. Therefore, patients agree to change the financing system for primary care services in order to enjoy greater access to cares. This payment method is called capitation designed for people with great needs in primary care (Kutzin \& Couffinhal, 2005).

Based on the existing laws and regulations, regional purchasing-service institutions in New Zealand are obliged to contract for all services. By separating the role of the buyers and health service providers and introducing the market for delivering services, it is expected to establish motives and financial incentives for greater efficiency and conformity of neoclassic economic theory with competitive market. It is also predicted that purchasing services through contract helps proper increase in delivering qualitative and quantitative services and ensure that the actual and suitable price is paid (WHO Report, 1993).

\section{Research Methods}

The present research is a kind of applied study conducted through descriptive-comparative method. With regard to the experiences of selected countries and studying the related theories and models, the variables affecting payment system for strategic purchasing in the indirect health section of Iranian Social Security Organization were identified. For this purpose, the most important variables which are necessary in a payment mechanism system were identified and a questionnaire was prepared based on the above variables and completed by the experts. The experts included 80 executive experts from the indirect health section of Iranian Social Security Organization and General Office of Medical Services.

The research was conducted in 5 stages:

Stage1: studying theoretical principles, examining related studies in the country and abroad,

Stage2: studying the experiences of other countries and the history of the issue in the Iranian Social Security Organization,

Stage3: defining effective variables on health care payment mechanism,

Stage4: preparing a questionnaire based on the identified variables and collecting the experts' views,

Stage5: verifying variables affecting health care payment mechanism through confirmatory and exploratory analysis factor by LISREl and SPSS softwares.

The validity of the questionnaire was determined through content validation method by 5 experts in strategic purchasing of health services and they were asked to express their opinions about the content and the style of the writing in a written form. The Ratio Content Validity was 0.98 which represented the content validity of the questionnaire. In fact, the exploratory analysis factor and its impact on determining the effective variables of payment mechanism for strategic purchasing implies that the questionnaire enjoys construct validity. The process of 
preparing and screening data started with the discussion about the multivariable normality, linearity, homogeneity of variance and multicollinearity. The common criterion to evaluate the normality is examining the statistical skewness and kurtosis. Kline (2005) believes that if skewness and kurtosis are between +2 and -2 , the data is normally distributed on the 0.05 level. The data of the present study shows that the statistical values of skewness and kurtosis are between +2 and -1.447 . So, the data has been distributed properly matrix scatter were used to determine the linearity of the relation among variables and the results showed that no relation among pointers indicated the obvious deviation from linearity. Leven Test was used to examine the variance in the research. $\mathrm{P}>0.05$ and $\mathrm{F}=2.197$ show that this hypothesis exists among the data of the study. Linearity happens when the internal correlation among variables is above 0.80 . This phenomenon makes any mathematical operation difficult. In order to determine the reliability of the questionnaire, it was given to the 10 members of the scientific board of the university who had a research background on the same subject; they answered the questions 2 times within two weeks and Alpha Chronboch coefficients were calculated $(0.71)$ to evaluate the internal coordination of the variables and correlation coefficient was determined 0.88 after re-testing.

\section{Findings}

According to table3, the average of the payment mechanism variables ranges from 3.35 to 4.32 . The average of the variables 8,4 and 12 were less than 3 . It can be said that there is an appropriate internal coordination among variables of payment mechanism.

Kaiser Maier Olkin index was 0.602 and significant level of Kroyt Bartlet index was less than 0.001 . Therefore, correlation matrix analysis in the selected group can be justified. Special value indicators, variance percentage and rotated chart of scree special values were examined to determine how many factors saturate payment mechanism variables. Based on these indicators, 3 factors were extracted from the total variables of payment mechanism which explain $51.03 \%$ of total variance. The first, second and third factors justify $22.54 \%, 17.1 \%$ and $11 / 43 \%$ of total variance of all the variables in payment mechanisms respectively. Table 4 shows load factor of payment mechanism variables on factors 1, 2, and 3 after Varimax rotation. Minimum accepted load factor was considered 0.4. The structure matrix is shown in table 4 . The extracted model was obtained after 5 rotations.

Three factors were extracted based on the structure matrix of variables. The minimum load factor $(0.379)$ belongs to variable 2 and the maximum load factor belongs to variable 6 . These factors were named according to the compound of each one of 1,2, and 3 factors in table 4: the first partial factor: performance-based payment system, the second partial factor: time-based payment system and the third partial factor: risk coverage.

The mathematical model extracted from the variables of payment mechanism in the process of strategic purchasing is a model with 3 partial dimensions including: performance-based payment system with 5 variables, time-based payment system with 4 variables, and risk coverage with 3 variables. Structural Equation Modeling (SEM) was used at this stage to verify the extracted model and determine the relationship among them. Figure 1 shows the related model.

Fitness indicators and $\mathrm{x}^{2} / \mathrm{df}$ for measuring model were considered 1.21 in the study, Comparative FI and GFI more than 0.9 and AGFI 0.88 and RMSEA 0.053; based on the obtained figures, it can be said that the present model has appropriate fitness with the data.

Moreover, coefficients of path analysis model for variables of payment mechanism were calculated (Table5). Based on this table, variable 2, establishing result-based payment system, had most parameter estimation.

Performance-based variables had 0.05 correlations with 0.52 coefficients with time-based variables at the level of probability. Covariance between variable errors 9 and 8 was -0.3 and between 4 and 7 was -0.19 . Level of probability in both cases was 0.05 . The impacts of variables 4,12 and 13 were not meaningful; as a result, they were omitted. In general, payment mechanism in the process of strategic purchasing considers triple dimensions of: performance-based payment system, time-based payment system, and risk coverage. 1- Performance-based payment system includes variables such as: financial incentives, forecasting, etc. 2- Time-based payment system includes variables such as time of receiving service, etc. 3- Risk coverage includes variables such as: justice, financial protection.

\section{Conclusion}

The findings of the present study about the variables affecting payment mechanism for strategic purchasing in the indirect health section of Iranian Social Security Organization indicates that payment mechanism has triple dimensions of performance-based, time-based, and risk coverage. In a research by Barnum et al. in 1995, payment level and unit and the time of payment as well as different payment systems (fee-for-service and capitation) and their strong and weak points were implied. Capitation payment method in national medicine system of England 
(Robinson \& Grand, 1994), Argentina (World Bank Report, 1998), New Zealand (Wilton \& Smith, 1998), and the United States (Feachem, 2000) has become operational. According to the World Health Organization Report in 2000, buyers must shift from payment mechanisms based on fee-for-service payment to those mechanisms covering risk; it is in accordance with the results of the present study. While examining the transition from the input-based payment system, bonus system and diagnostic affiliated groups are considered as well (Buss, 2008). The results of the present study emphasize on payment variables mechanism based on the results and bonus.

In a research conducted in Canada in 1999, the results focus on the increase of performance and the result of the purchasing system, which are among the expected results of strategic purchasing process and are consistent with the results of the present study about the performance-based payment mechanism. Langenbrunner et al. (2005) conducted a research in which they focused on time-based payment mechanisms, type of services and population, and payment system based on performance and delivered services and activities of diagnostic affiliated groups. Moreover, they examined performance-related payment systems and their results. According to their report, payment system is founded generally on prospective payment systems and has the ability to predict costs and forecasting, which is in accordance with the results of the present research in selecting performance-based and time-based payment mechanism.

The results of studying "shifting risk to service providers" and enhancement of production method and choosing risk by Manning (1998) confirms the results of the present study about the quality of delivered services. The research conducted by Langenbrunner et al. in 2005 affirms that most west European countries have chosen performance-based strategy in their payment system in hospitals. This system was used in Austria at the beginning of 1990s. Bocken (2008) in his researches considered establishing financial incentives and bonuses for health care providers (physicians) to improve the quality of care. Chalkley \& Mcvicar (2008) carried out a research about payment system based on results of health care providers which is now being used in England. Langenbrunner et al. (2005) pointed to risk sharing, level of risk (group against individual) and protection (financial coverage) and justice against disease.

The result of the present study is applicable to those organizations involved in the process of purchasing health services. It can also be used in payment systems to service providers, physicians, etc. It is also important to mention that before the mechanism becomes operational, the payment systems and the current situation in any system must be examined and decisions should be made upon the obtained results of the survey. Meanwhile, the managers in the health field should be trained as well.

Finally, it becomes clear that payment mechanism enjoys special importance in the process of strategic purchasing and officials and authorities of health field should pay attention to it. Utilizing identified variables will be effective in improving the purchasing process in the Iranian Social Security Organization and other insurance organizations.

\section{References}

Aaron, H. J. (1991). Serious and unstable condition; financing Americans health care, Washington DC.

Barnum, H. kutzin, J. \& Saxenian, H. (1995). Incentives and provider payment methods. International Journal of Health Planning and Management, 10: 23-45.

Bocken, J. (2008). Unterschiede in der Inanspruchnahme von Facharzten in der hausarztichen und in der hausarztzentrierten versorgung. Eine Analyse auf der Grundiage ausgewahlter fragen des Gesundheitsmonitors. To be published in: Das Gesundheitsweseen. Autumn.

Borges C., M. \& Condoso, M., De F. (2008). International workshop- Gover nance of strategic purchasing in health sector may 14-15 (Bled) Slovenia, unidade operacional de financiamento contratualizaco.

Boyle, S. (2007). Payment by results in England. Eurohealth, pp. 13, 12-16.

Buss, R. (2004, 2008).,[Online] Available: European observatory on health systems and policies (July 10, 2010)

Chalkley, M. \& Mc Vicar, D. (2008). Choice of Contracts in the British National Health Service: An empirical study. Journal of Health Economics. Pp. 27, 1155-1167.

Department of Health, (1993). Whaia te Ora mo te iwi: Maori Health Policy Guidelines to Regional Health. Authorities and the Public Health commission. Wellington: Department of Health.

Feachem, S. N. (2000). Managed care: the US experience. Bulleting of the World Health Organization, 78 (6) (in press).

Grignon, M., Paris, V. Polton, D. Couffinhal, A. \& Pierrard, B. (2004). The Influence of Physician Payment Methods on the Efficiency of the Health Care System, in Changing Health Care in Canada, Romanow Papers, Vol 2, P. -G. Forrest, G. Marchildon, T. Mclnstosh (Ed), University of Toronto Press, pp. 207-239. 
Habicht, J. K, X. Couffinhal, A. \& Kutzin, J. (2005). Out-of-pocket Payments in Estonia: An Object for Concern? HSF Working Document, Health Systems Financing Programme, WHO Regional Office for Europe.

Hasanzadeh, A., \& Fakhimzadeh, S. (2006). Organizational Reforms in Hospitals, Utilizing Market Interactions in Managing a Hospital, Tehran, High Research Institute of Social Security Organization.

Kline, R. B. (2005). Principles and practice of structural equation modeling. New York: The Gilford press.

Kutzin, J. \& Couffinhal, A. (2005). Health Financing in Estonia: Challenges and Recommon dation, WHO Regional office for Europe, Health system Financing, CopenHagen, February.

Langenbrunner, J. C. Orosz, E. Kutzin, J. \& Wiley, M. M. (2005). Textbook Purchasing and paying provider. (Chapt 11).

Manning, N. (1998) Unbundling the state: Autonomous Agencies and service Delivery, Draft world bank Discussion paper. Washington, DC: World Bank.

O'Neill, C. \& Largey, A. (1998). The role of quality standords- accreditation in redressing asymmetry of Information in health care Markets. Health Policy, pp. 45, 33- 45.

Preker, A. S. \& Harding, A. (2003). Innovation in Health Corporatization of public Hospital. Washington, DC. The World Bank. ISBNO-8213-4994-39. Part1 Overview of Market zing organizational Reforms (Chapters 1).

Preker, A. S. \& liu, X. edit. Velenyi, V. \& Baris, E. (2007). Public ends private means strategic purchasing of health services, The World Bank Washington DC. 20433 (Chapter 11).

Robinson, R. \& Le Grand, J. (1994). Evaluating the National Health Service reforms. Oxford Health Policy Joumals, Transaction Books.

Statistical Indicators Report of the Social Security Organization, Health Department, 2008, No. $15^{\text {th }}$, Iran, Tehran, Social Security Organization

Wilton, P. \& Smith, R. D. (1998). Primary care reform: a three country comparison of budget holding. Health Policy, 44 (2), pp. 149-166.

Workplace Safety and Insurance board health Care Model, Canada (1999).

World Bank, Argentina. (1998). Facing the challenge of health insurance reform. Washington, DC, The World Bank, (LASHD ESW Report 16402- AR).

World Health Organization (2000). The World Health Report: Improving Health system performance. Geneva: WHO.

Table 1. Impact of payment motivation in different methods (Preker et al, 2007)

\begin{tabular}{|c|c|c|c|c|c|c|}
\hline \multirow{2}{*}{ Payment Method } & \multirow{2}{*}{ Risk to } & $\begin{array}{c}\text { Access/financial } \\
\text { Protection }\end{array}$ & Quality & Expenditure & Efficiency & $\begin{array}{c}\text { Simplicity of } \\
\text { implementation }\end{array}$ \\
\cline { 3 - 7 } & Provider & + & + & +++ & & ++ \\
\hline Line item budget & Buyer & ++++++ & ++ & +++ & + & +++ \\
\hline Salary & Buyer & & ++ & & & + \\
\hline FFS incentive & Buyer & & + & & & + \\
\hline In-patient Day & Provider & & ++ & + & +++ & + \\
\hline Per case & Provider & + & ++ & ++ & + & + \\
\hline Global budget & Provider & + & + & +++ & +++ & + \\
\hline Capitation & Buyer & + & ++ & + & + & + \\
\hline $\begin{array}{c}\text { Performance-based } \\
\text { payment }\end{array}$ & & & & & + \\
\hline
\end{tabular}


Table 2. Payment mechanism to the health care providers

\begin{tabular}{|c|c|c|c|c|}
\hline Payment Mechanism & Preventing Health Problems & Delivering Services & Responding to Legal Expectations & Reducing Costs \\
\hline Line item budget & $+/-$ & -- & $+/-$ & +++ \\
\hline Global budget & ++ & -- & $+/-$ & +++ \\
\hline Capitation (with competition ) & +++ & -- & ++ & +++ \\
\hline Diagnostic-Related Group (DRG) & $+/-$ & ++ & ++ & ++ \\
\hline Fee for Service & $+/-$ & +++ & +++ & -- \\
\hline
\end{tabular}

+++ : very high positive effect

++ : limited positive effect $\quad+/$-: low or nothing effect

: very low negative effect

_ _: limited negative effect world health report, 2000

Table 3. Average and standard deviation for the variables of payment mechanism for strategic purchasing

\begin{tabular}{|l|l|c|c|}
\hline Row & Variables & Average & Standard Deviation \\
\hline 1 & Creating motivation and financial incentives for health care providers & 4.32 & 0.776 \\
\hline 2 & Establishing result-based payment system with efficiency in health system & 4.31 & 0.645 \\
\hline 3 & Creating performance-based motivations for the employees of the health field & 4.21 & 0.650 \\
\hline 4 & Direct payment to service providers & 2.24 & 1.275 \\
\hline 5 & Indirect payment to service providers & 3.80 & 0.786 \\
\hline 6 & Justice against disease risk & 3.99 & 0.716 \\
\hline 7 & Financial protection against disease risk & 4.06 & 0.731 \\
\hline 8 & Transferring financial risk to service providers & 2.89 & 1.245 \\
\hline 9 & Ability to predict costs and prospective payment system & 4.23 & 0.597 \\
\hline 10 & Retrospective payment including: bonus payment/salary/fee for service & 2.98 & 0.925 \\
\hline 11 & Retrospective payment including: case payment, daily payment, capitation payment and budget & 3.91 & 0.925 \\
\hline 12 & Unit Payment & 3.35 & 1.06 \\
\hline 13 & Payment method based on D.R.G & 3.96 & 0.887 \\
\hline
\end{tabular}

Table 4. Load factor of payment mechanism variables on factors 1, 2, and 3 after Varimax rotation

\begin{tabular}{|c|c|c|c|}
\hline Variable & First factor & Second factor & Third factor \\
\hline 4 & 0.817 & & \\
\hline 12 & 0.623 & & \\
\hline 9 & 0.601 & & \\
\hline 13 & 0.459 & & \\
\hline 10 & & 0.708 & \\
\hline 11 & & 0.661 & \\
\hline 3 & & 0.629 & \\
\hline 5 & & 0.568 & \\
\hline 6 & & & 0.787 \\
\hline 7 & & & 0.738 \\
\hline 1 & & & 0.576 \\
\hline 8 & & & 0.525 \\
\hline 2 & & & 0.379 \\
\hline
\end{tabular}


Table 5. Coefficients of path analysis model in payment mechanism

\begin{tabular}{|l|c|c|c|c|}
\hline \multicolumn{1}{|c|}{ Latent variables } & Parameter estimation & $\mathrm{t}$ & Standard deviation & $\mathrm{R}^{2}$ \\
\hline 1- performance-based & 0.35 & 3.89 & 0.47 & $0.20^{*}$ \\
\hline 2- performance-based & 0.66 & 5.54 & 0.089 & $0.78^{* *}$ \\
\hline 2- time-based & -0.34 & -2.82 & & \\
\hline 3- performance-based & 0.50 & 7.23 & 0.17 & $0.60^{* *}$ \\
\hline 5- time-based & 0.38 & 3.18 & 0.47 & $0.24^{*}$ \\
\hline 6- performance-based & 0.29 & 3.95 & 0.21 & $0.57^{* *}$ \\
\hline 6- risk coverage & 0.45 & 4.06 & & \\
\hline 7- risk coverage & 0.49 & 3.96 & 0.31 & $0.40^{* *}$ \\
\hline 8- risk coverage & 0.48 & 3.19 & 0.89 & $0.20^{*}$ \\
\hline 9- performance-based & 0.23 & 3.69 & 0.31 & $0.18^{*}$ \\
\hline 10- time based & 0.62 & 5.66 & 0.29 & $0.50^{* *}$ \\
\hline 11- time based & 0.48 & 4.10 & 0.27 & $0.27^{*}$ \\
\hline
\end{tabular}

$* \mathrm{P}<0.05 \quad * * \mathrm{P}<0.01$

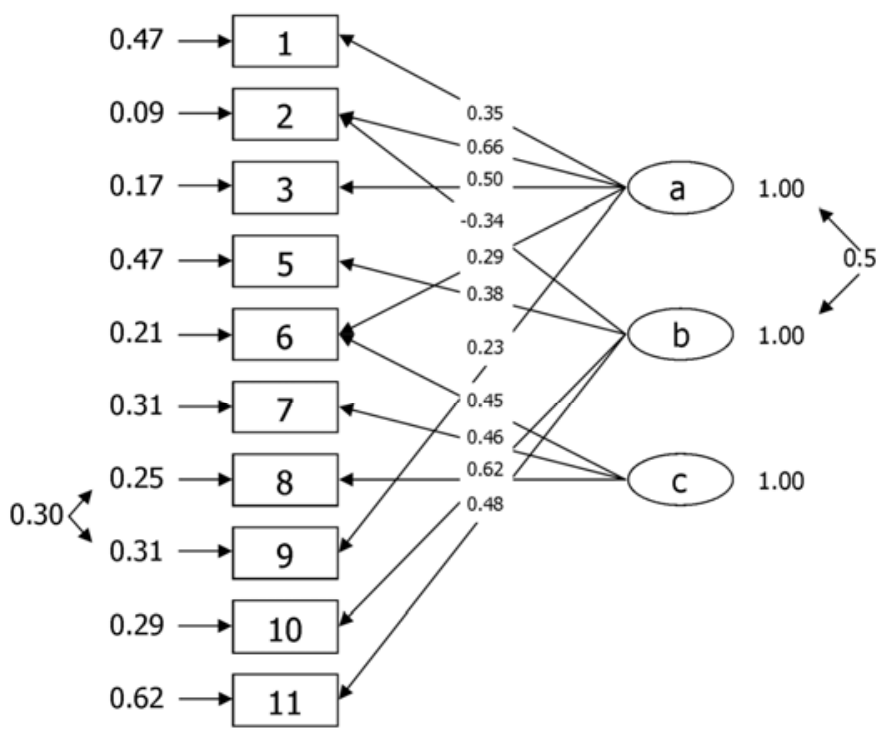

Chi-Square $=38.03, \quad \mathrm{df}=31, \quad \mathrm{p}$-value $=0.17972 \quad$ RMSEA $=0.053$

Figure1. The model of payment mechanism for strategic purchasing in health sector of ISSO

(Performance-based, time-based, and risk coverage partial dimensions) 